\title{
INCIDÊNCIA DE FERRUGEM EM FOLHAS DE PESSEGUEIRO E NECTARINEIRA DO GERMOPLASMA IAC ${ }^{1}$
}

\author{
W. BARBOSA²; F.A.CAMPO-DALL'ORTO²; M. OJIMA; G.P.C. KALIL; A.A. LOVATE; I.J.A. \\ RIBEIRO ${ }^{2}$ \\ Instituto Agronómico de Campinas, C.P. 28 - CEP: 13001-970 - Campinas,SP \\ F.P. MARTINS \\ Estafão Experimental de Jundiat/IAC, C.P. 11 - CEP: 13200-970 - Jundiat,SP \\ E.M.C. NOGUEIRA ${ }^{2}$ \\ Instituto Biológico de São Paulo, C.P. 7119 - CEP: 04014-000 - São Paulo,SP
}

\begin{abstract}
Resmo: Avaliou-se, em fins do verāo de 1993, o grau de incidência da ferrugem (Tranzschelia discolor $\mathbf{f}$. sp. domesticae), em dezoito seleçōes IAC de pessegueiro e seis de nectarineira, mantidos em lote de germoplasma na Estação Experimental de Jundiar (23\% $08^{\prime}$ 'S; $\left.46^{\circ} 55^{\prime} \mathrm{W}\right)$. A porcentagem de incidéncia do pat 6 geno foi estimada através de observações macroscópicas das folhas, atribuindo-se notas de 1 a 5 (1 = nula, $2=$ leve, $3=$ moderada, $4=$ severa, 5 = muito severa), conforme o grau da severidade do sintoma. Todo o material pesquisado mostrou-se suceptível ao patogeno, entretanto, as seleçōes apresentaram sensíveis variaçōes em graus de susceptibilidade. As seleções com maior tolerância ao patogeno foram: 1) pêssegos 'Régis' e IAC $4685-45$ e 2) nectarinas 'Josefina' e IAC N 2680-91.
\end{abstract}

Descritores: pêssego, nectarina, ferrugem, Tranzschelia discolor f. sp. domesticae, resistência, seleções IAC.

\section{INCIDENCE OF RUST LEAF DISEASE ON PEACHES AND NECTARINES OF THE IAC GERMOPLASM BANK}

\begin{abstract}
The occurrence of rust leaf disease (Tranzschelia discolor $f$. sp domesticae) was verified in 24 peach and nectarine selections at the Jundiá Experimental Station $\left(23^{\circ} 08^{\prime} \mathrm{S}\right.$ and $\left.46^{\circ} 55^{\prime} \mathrm{W}\right)$ State of São Paulo, Brazil. The trees of the germoplasm bank were evaluated using a sympton scale to evaluate selection susceptibility to the pathogen, at different levels. The less susceptible selections were: 1) peaches 'Regis' and IAC $4685-45$ and 2) nectarines 'Josefina' and IAC N 2680-91.

Key words: peach, nectarine, rust, Tranzschelia discolor $\mathbf{f}$. sp. domesticae, resistance, IAC selections.

\section{INTRODUÇĀO}

A ferrugem, doença causada pelo fungo Tranzscheliadiscolor f.sp. domesticae, constitui um dos problemas mais sérios nas culturas de pessegueiros e nectarineiras. Quando sua incidência é severa, causa queda prematura das folhas principal órgão afetado - debilitando os ramos de frutificação. Essa queda extemporânea de folhas afeta, ainda, o equilibrio fisiológico das plantas, podendo proporcionar duas florações anuais, esgotando, assim, as reservas nutricionais, prejudi-

cando a produção e a vida útil do material (BLEICHER \& TANAKA, 1982; CAMPO DALL'ORTO et al., 1984; FELICIANO \& ARAÚJO, 1979; ANDERSON, 1956; KANG \& KO, 1976). A infecção inicial da planta ocorre com - aumento da umidade e temperatura, que propiciam a germinação dos uredos-poros. Estes, possuindo uma longevidade máxima de 150 dias, estão aptos à reinfecção das folhas, sob as condições dos dias chuvosos da primavera e verão. Daí a necessidade dos tratamentos rigorosos de inverno para a eliminação ou diminuição das fontes
\end{abstract}

1 Trabalho integrante do Projeto IAC: "Manutenção de Germoplasma de Frutíferas de Clima Temperado".

${ }^{2}$ Bolsista do CNPq.

Sci. agric., Piracicaba, 51(1):90-93, jan./abr., 1994 
de inóculo, em campo, evitando-se a reciclagem da doença (BLEICHER \& TANAKA, 1982; CAMPO DALL' ORTO et al. 1984; BARBOSA et al., 1990; THAKUR et al., 1991), assim como as pulverizações fúngicas preventivo-curativas, principalmente na fase vegetativa das plantas.

Verificam-se, em lotes de germoplasma de frutíferas de caroço, diferentes níveis de infecção de ferrugem, detectados pelo maior ou menor enfolhamento das plantas no final do verão. Este fato pode estar relacionado a fatores extra ambientais, ou seja, a presença de material mais tolerante à ferrugem, importante como fonte de resistência ao patógeno. A detecção de cultivares menos susceptíveis à doença, constitui avanço para utilização em pomares comerciais, diminuindo a freqüencia dos onerosos tratos fitossanitários.

Este trabalho trata do levantamento preliminar da incidência da ferrugem, em coleções de pessegueiros e nectarineiras nas condições ecológicas de Jundiaí, SP. Procurou-se assim, obter maiores conhecimentos sobre as seleções IAC dessas frutíferas, avaliando a susceptibilidade relativa à ferrugem, como subsídio aos trabalhos de melhoramento.

\section{MATERIAL E MÉTODOS}

Utilizaram-se na experimentação seleções de pessegueiros e nectarineiras do germoplasma situado na Estação Experimental de Jundiaí ( $23^{\circ} 08^{\prime} . ; 46^{\circ} 55^{\prime} \mathrm{W}$. e $\left.80 \mathrm{HF}-7^{\circ} \mathrm{C}\right)^{1}$, do IAC. São elas: pêssegos 'Jóia-1', 'Jóia-3', 'Jóia-5', 'Dourado-1', 'Dourado-2', 'Aurora-1', 'Aurora-2', 'Tropical', 'Delicioso Precoce','Régis', IAC 68013, IAC 280-28, IAC 6782-83, IAC 6882-37, IAC 785-1, IAC 4685-45, e IAC 2982-32 e nectarinas 'Centenária', 'Josefina', 'Rosalina', IAC N 188062 , IAC N 2680-91 e IAC N 1880-3. Os tratos culturais do pomar foram similares aos rotineiramente recomendados à cultura (OJIMA et al., 1990).

Para avaliação da ferrugem em laboratório coletaram-se, ao acaso, de três plantas por seleção, 100 folhas da porção mediana da copa e dos ramos. As coletas foram realizadas na primeira quinzena de março de 1993. A incidência da ferrugem nas folhas foi estimada através de

\footnotetext{
'Latitude, longitude e horas anuais de frio abaixo de $7^{\circ} \mathrm{C}$, respectivamente (PEDRO JUNIOR et al., 1979).
}

observações macroscópicas das pústulas, atribuindo notas de 1 a 5 , conforme padrão anteriormente adotado para ameixeira (CAMPO DALL'ORTO et al., 1979 e 1980), sendo: 1 = nula, 2 = leve, $3=$ moderada, $4=$ severa, $5=$ muito severa. Ao ítem enfolhamento da planta foram atribuídas no campo as seguintes notas: $1=$ fraco, $2=$ médio, $3=$ forte

As observações das plantas, as amostragens das folhas $e$ a análise laboratorial foram realizadas por três pessoas. Assim, a nota para incidência de ferrugem e grau de enfolhamento de cada material, correspondeu à média em porcentagem das concedidas pelos três avaliadores.

\section{RESULTADOS E DISCUSSÃO}

Todos os pessegueiros e nectarineiras avaliados mostraram-se susceptíveis à ferrugem (Figura 1). No entanto, as seleções apresentaram diferentes níveis de susceptibilidade, variando desde o pêssego IAC 6882-37, seleção mais susceptível, com $81,67 \%$ de incidência severa e muito severa, à nectarina 'Josefina', a mais tolerante, com somente $12,33 \%$.

Os pêssegos 'Régis' e IAC 4685-45 e as nectarinas 'Josefina' e IAC N 2680-91, com menores índices de incidência da doença $\leq 30 \%$ de incidência severa e muito severa), corresponderam às seleções com melhor enfolhamento das plantas (nota média de 2,2). Essas seleções, seguidas de outras que mostravam também bom comportamento - 'Delicioso Precoce' IAC N 18803, 'Tropical' e 'Rosalina' - sugerem ser mais tolerantes ao patógeno, merecendo atenção especial na utilização nos trabalhos de melhoramento.

Por outro lado, as seleções de pêssegos IAC 6882-37, IAC 680-13, 'J6ia-1', 'Jóia-5' e IAC 280-28, com altos índices de incidência severa e muito severa (ao redor de $60 \%$ e acima), indicam tratar-se de material que carece de maiores cuidados no monitoramento da doença e nos tratos fitossanitários com produtos fúngicos.

Os resultados obtidos neste trabalho necessitam ainda de averiguações mais aprofundadas. $\mathbf{E}$ interessante que sejam analisados o início da infecção da planta, o período de maior incidência e o controle da ferrugem, frente às condições ecológicas locais. De um lado, seriam detectadas as seleções mais sensíveis ao patógeno e aos desequilibrios fisiológicos e nutricionais, responsáveis pela diminuição da produção e da vida útil do pomar (ANDERSON,1956; FELICIANO et 
Incidência de ferrugem, $z$

IAC $6882-37$

IAC $680-13$

JöIA - 1

JÖIA -5

IAC $\quad 280-28$

DOURADO-1

IAC 2982-32

IAC $6782-83$

CENTENÄRIA

IAC $\quad 6982-2$

IAC $\quad 785-1$

IAC N 1880-62

DOURADO -2

ROSALINA

AURORA - 1

AURORA - 2

JŌIA -2

TROP ICAL

IAC $N 1880-3$

DELICIOSO PRECOCE

RËGIS 1

IAC $\quad 4685-45$

IAC N 2680-91

JOSEFINA

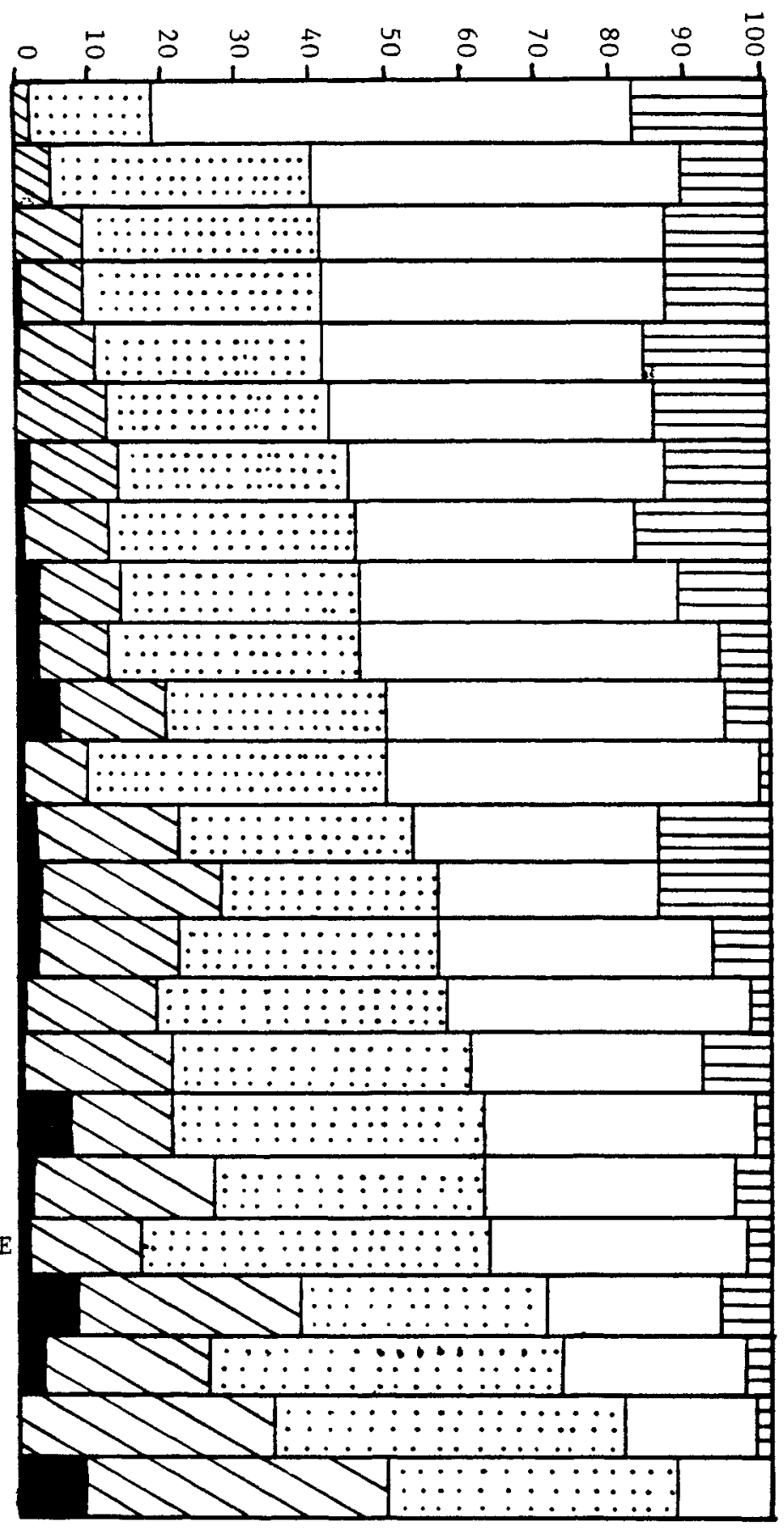

Figura 1 - Porcentagem de incidência de ferrugem (Tranzschelia discolor F. sp. domesticae) de pessegueiro e nectarineira do banco de germoplasma do IAC, Jundiaí,SP. 
al., 1979; BLEICHER \& TANAKA, 1982; KANG \& KO, 1976). De outro lado, poder-se-iam selecionar pessegueiros e nectarineiras que confirmassem as características de tolerância ou resistência da ferrugem, constituindo material genético útil aos trabalhos de cruzamentos controlados.

\section{CONCLUSÕES}

1. Todas seleções de pessegueiros e nectarineiras analisadas mostraram-se susceptiveis à ferrugem. No entanto, houve variações em graus de susceptibilidade entre as seleções.

2. Os pessegueiros 'Régis' e IAC 4685-45, e as nectarineiras 'Josefina' e IAC N 2680-91 apresentaram-se mais tolerantes à doença, com plantas de melhor enfolhamento.

\section{AGRADECIMENTOS}

Os autores agradecem aos Técnicos de Apoio, MEIRE CORREIA DA SILVA FERRARI e MARCILENE DE MORAIS, o auxílio na coleta e análise das folhas dos pessegueiros e nectarineiras do experimento.

\section{REFERÊNCIAS BIBLIOGRÁFICAS}

ANDERSON, H.W. Leaf blight and fruit spot of pear and quince.In: . Disenses of fruit crops. New York: Mc Graw Hill, 1956. p.201-205.

BARBOSA, W.; CAMPO DALL'ORTO, F.A.; OIMA, M.; SAMPAIO, V.R.; BANDEL, G. Ecofisiologia do desenvolvimento vegetativo e reprodutivo do pessegueiro em região subtropical. Campinas: Instituto Agronômico, 1990. 37p. (IAC. Documentos, 17)

BLEICHER, J.; TANAKA, H. Doencas do pessegueiro no Estado de Santa Catarina. 2.ed. Florianópolis, EMPASC, 1982. 53p.
CAMPO DALL'ORTO, F.A.; OJMA, M.; RIBEIRO,I.J.A.; RIGITANO,O.; ALVES, S. Resistência varietal da ameixeira à ferrugem (Tranzschelia spp.) nas condiçōes de Monte Alegre do Sul,SP. Bragantia, Campinas, v.39, p.171-174, 1980. (Nota, 3).

CAMPO DALL'ORTO, F.A.; OJMA, M.; BARBOSA, W.; RIGTTANO, O.; SANTOS, R.R.; BETTI, J.A. Recuperação de ameixeiras improdutivas. Campinas: Instituto Agronômico, 1984. 8p. (IAC. Boletim Técnico, 31)

CAMPO DALL'ORTO, F.A.; OIMA, M.; RIBEIRO, I.J.A.; RIGITANO, O.; VEIGA, A.A. Resistência varietal de ameixeira (Prunus salicina Lindl.) à ferrugem (Tranzschelia spp.) nas condições de TietêSP, In: CONGRESSO BRASILEIRO DE FRUTICULTURA,5., 1979, Pelotas, Anais... Pelotas: Sociedade Brasileira de Fruticultura, 1979. v.2, p.789-796.

FELICIANO, A.; ARAÚJO, P.F. Ferrugem das fruteiras de caroço I. Eficiência de diferentes fungicidas no controle da ferrugem do pessegueiro causado por Tranzschelia spp. In: CONGRESSO BRASILEIRO DE FRUTICULTURA, 5., 1979, Pelotas, Anais... Pelotas: Sociedade Brasileira de Fruticultura, 1979. p.724-727.

KANG, S.M.; KO, K.C. A study of cold hardiness, flowering and bearing in "Okubo" peach trees (Prunus persica) as affected by defoliation, Journal of the Korean Society for Horticultural Science, Suwon, v.17, n.1, p.1-11, 1976.

THAKUR, V.S.V;; GUPTA, V.K.; GARC, R.C. Management of fungal diseases of stone fruits with fungicides in Himachal Pradesh. Indian Journal of Agricultural Sciences, New Delhi, v.61, n.9, p.677-681, 1991 .

Enviado para publicação em 13.07.93

Aceito para publicação 13.12.93 